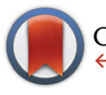

CrossMark $\leftarrow$ click for updates

Cite this: Dalton Trans., 2015, 44 6219

Received 14th January 2015, Accepted 19th February 2015

DOI: $10.1039 / c 5 d t 00183 h$

www.rsc.org/dalton

\section{Radical-cation salts of BEDT-TTF with lithium tris(oxalato)metallate(III) $\dagger$}

\author{
Lee Martin, ${ }^{\text {a }}$ Hendrik Engelkamp, ${ }^{a}$ Hiroki Akutsu, ${ }^{\text {b,c }}$ Shin'ichi Nakatsuji, \\ Jun'ichi Yamada, ${ }^{c}$ Peter Horton ${ }^{d}$ and Michael B. Hursthouse ${ }^{d}$
}

The first radical-cation salts in the extensive family (BEDT-TTF) $x_{x}\left[(A) M\left(C_{2} \mathrm{O}_{4}\right)_{3}\right]$. Guest containing lithium as the counter cation have been synthesized and characterised.
Crystal engineering of bis(ethylenedithio)tetrathiafulvane (BEDT-TTF) radical-cation salts has been investigated extensively to combine various physical properties in the segregated anionic and cationic layers. The largest known family of these salts is that of BEDT-TTF with tris(oxalato)metallate anions which combine magnetism with a variety of electronic ground states. This family of salts has the general formula (BEDT-TTF $)_{x}\left[(\mathrm{~A}) \mathrm{M}^{3+}\left(\mathrm{C}_{2} \mathrm{O}_{4}\right)_{3}\right] \cdot$ Guest $\left(\mathrm{A}=\mathrm{K}^{+}, \mathrm{H}_{3} \mathrm{O}^{+}, \mathrm{NH}_{4}{ }^{+} ; \mathrm{M}^{3+}=\mathrm{Fe},{ }^{1}\right.$ $\left.\mathrm{Cr},{ }^{2} \mathrm{Ga},{ }^{3} \mathrm{Al},{ }^{4} \mathrm{Co},{ }^{4} \mathrm{Ru},{ }^{5} \mathrm{Cu}^{6}\right)$ which crystallise in a number of different polymorphs. The packing arrangement of the donor layers, and therefore conducting behaviour of these salts, is influenced by the packing arrangement of the anionic layers. The tris(oxalato)metallate anions form a hexagonal network with the counter cation (A) producing a honeycomb of cavities which are able to include a guest molecule of the electrolyte which is being used for the electrochemical synthesis. Changes to the size and shape of this guest electrolyte molecule leads to changes in the hydrogen bonding interactions between the insulating anionic layer and the conducting cationic layer. Subtle changes to packing of this cationic layer produces a range of electronic ground states. ${ }^{7}$

$\beta^{\prime \prime}$ donor packing is observed in the majority of these salts and has shown superconductivity in many cases $\left(\mathrm{M}=\mathrm{Fe}^{3+}\right.$, Guest $\left.=\mathrm{PhCN}, \mathrm{PhNO}_{2}, \mathrm{PhBr}, \mathrm{PhF}\right)$, metallic $\left(\mathrm{M}=\mathrm{Fe}^{3+}\right.$, Guest $=$ $\mathrm{PhCl}, \mathrm{DMF})$, semiconducting $\left(\mathrm{M}=\mathrm{Fe}^{3+}\right.$, Guest $\left.=\mathrm{PhI}\right)$ or metalinsulator behaviour $\left(\mathrm{M}=\mathrm{Fe}^{3+}\right.$, Guest $=$ dichloromethane or pyridine). ${ }^{7}$

\footnotetext{
${ }^{a}$ School of Science and Technology, Nottingham Trent University, Clifton Lane, Clifton, Nottingham, NG11 8NS, UK. E-mail: lee.martin@ntu.ac.uk; Tel: +44 (o)1158483128

${ }^{b}$ Department of Chemistry, Graduate School of Science, Osaka University, 1-1 Machikaneyama-cho, Toyonaka, Osaka 560-0043, Japan

${ }^{c}$ Graduate School of Material Science, University of Hyogo, Kamigori-cho, Ako-gun, Hyogo 678-1297, Japan

${ }^{d}$ School of Chemistry, Faculty of Natural and Environmental Sciences, University of Southampton, Highfield, Southampton, SO17 1BJ, UK

$\dagger$ CCDC 1042692, 1042694 and 1042696. For crystallographic data in CIF or other electronic format see DOI: 10.1039/c5dt00183h
}

In some cases the electrolyte molecule is too large to be included in the hexagonal cavity e.g. 1,2,4-trichlorobenzene, ${ }^{8}$ carvone. ${ }^{9}$ However it has been shown that 1,2,4-trichlorobenzene is an excellent solvent in which to grow crystals of this type in combination with a smaller guest molecule plus ethanol. ${ }^{8}$

Different polymorphs have been observed when the guest electrolyte molecule is only slightly too large to fit within the cavity. These molecules are arranged asymmetrically within the cavity and some part of the molecule will protrude from the anionic layer into the cationic layer. This results in the two faces of the anionic layer presenting a different face to each adjacent cationic layer which leads to alternate cationic layers having different donor packing motifs and different electronic ground states. $\alpha$-Pseudo- $\kappa$ packing has been observed with metallic behaviour (Guest $=1,2$-dibromobenzene) ${ }^{10}$ whilst a metal-insulator transition is observed in the $\alpha-\beta$ " phases $\left(\right.$ Guest $=\mathrm{PhN}\left(\mathrm{CH}_{3}\right) \mathrm{COH}, \mathrm{PhCH}_{2} \mathrm{CN}$ or $\left.\mathrm{PhCOCH}_{3}\right) .{ }^{11}$ Another $\alpha-\beta$ " phase is found with $s e c$-phenethyl alcohol as guest molecule showing small differences in the metal-insulator behaviour depending on whether racemic or a single enantiomer of the electrolye is used. ${ }^{11}$

The distribution of the enantiomers of tris(oxalato)metallate can also lead to different polymorphs with different electronic properties. In the $\beta^{\prime \prime}$ salts each anion layer consists of only a single enantiomer, with neighbouring layers consisting of only the opposite enantiomer. When synthesising these crystals from enantipure $\mathrm{M}\left(\mathrm{C}_{2} \mathrm{O}_{4}\right)_{3}$ racemisation occurs during growth and leads to a semiconducting polymorph with a psuedo-k donor packing motif and anionic layers which contains a $50: 50$ mixture of $\Delta$ - and $\left.\Lambda-\mathrm{M}_{(} \mathrm{C}_{2} \mathrm{O}_{4}\right)_{3}$ in alternate rows. ${ }^{12}$

Research on these salts has focussed on the use of $\mathrm{K}^{+}$and $\mathrm{NH}_{4}{ }^{+}$as the counter cations. We recently reported the inclusion of $\mathrm{Na}^{+}$in the first chiral examples of this family synthesised using electrocrystallisation from chiral electrolyte $(R)$ carvone and racemic $\mathrm{Na}_{3} \mathrm{Cr}\left(\mathrm{C}_{2} \mathrm{O}_{4}\right)_{3}$ to give semiconducting (BEDT-TTF $)_{3} \mathrm{NaCr}\left(\mathrm{C}_{2} \mathrm{O}_{4}\right)_{3}$. Guest containing a single enantiomer of $\mathrm{Cr}\left(\mathrm{C}_{2} \mathrm{O}_{4}\right)_{3} \cdot{ }^{9}$ 
In this work we report the synthesis and characterisation of a new polymorph in the first BEDT-TTF salts in this family by introducing lithium as the counter cation.

\section{Experimental}

\section{Synthesis and purification of starting materials}

$\mathrm{Li}_{3} \mathrm{Cr}\left(\mathrm{C}_{2} \mathrm{O}_{4}\right)_{3}$ and $\mathrm{Li}_{3} \mathrm{Fe}\left(\mathrm{C}_{2} \mathrm{O}_{4}\right)_{3}$ were synthesised by an adaptation of the method of Bailar and Jones. ${ }^{13}$ BEDT-TTF, acetonitrile, dichloromethane, ethanol, L-carvone and 12-crown-4 (Aldrich) were used as received.

Electrocrystallisations were carried out in conventional $\mathrm{H}$-shaped cells with a volume of $40 \mathrm{~mL}$ containing $10 \mathrm{mg}$ BEDT-TTF in the anode compartment. H-cells were placed in sand-filled compartments in the dark at constant temperature of $293 \mathrm{~K}$. The H-cells had two platinum electrodes, separated by a porous glass frit to prevent contamination. The electrodes were cleaned by applying a voltage across the electrodes in $1 \mathrm{M}$ $\mathrm{H}_{2} \mathrm{SO}_{4}$ in each direction resulting in the evolution of $\mathrm{H}_{2}$ and $\mathrm{O}_{2}$ at the electrodes. Finally the electrodes were washed in distilled water and thoroughly dried.

\section{Synthesis of (BEDT-TTF $)_{4}\left(\mathrm{H}_{2} \mathrm{O}\right) \mathrm{LiFe}\left(\mathrm{C}_{2} \mathrm{O}_{4}\right)_{3}$ (I)}

$120 \mathrm{mg} \mathrm{Li}{ }_{3} \mathrm{Fe}\left(\mathrm{C}_{2} \mathrm{O}_{4}\right)_{3}$ and $15 \mathrm{mg}$ 12-crown-4 crown ether were mixed for six hours in $10 \mathrm{~mL}$ acetonitrile and $10 \mathrm{~mL}$ dichloromethane. The solution was transferred to the $\mathrm{H}$-cell and a layer of $2 \mathrm{~mL}$ water was added to the anode side of the $\mathrm{H}$-cell. A constant current of $1.0 \mu \mathrm{A}$ was passed through the solution in a H-shaped cell and black spear-shaped crystals grew on the anode and were collected after 6 days.

\section{Synthesis of (BEDT-TTF) $)_{3} \operatorname{LiCr}\left(\mathrm{C}_{2} \mathrm{O}_{4}\right)_{3} \cdot$ ethanol (II)}

$134 \mathrm{mg} \mathrm{Li}_{3} \mathrm{Cr}\left(\mathrm{C}_{2} \mathrm{O}_{4}\right)_{3}$ and 5 drops of 12-crown-4 crown ether were mixed in $20 \mathrm{~mL} \mathrm{~L}$-carvone and $20 \mathrm{~mL}$ ethanol for three hours. A constant current of $0.1 \mu \mathrm{A}$ was passed through the solution in a H-shaped cell and black crystals grew on the anode and were collected after 1 month.

\section{Synthesis of (BEDT-TTF $)_{3} \mathrm{LiFe}\left(\mathrm{C}_{2} \mathrm{O}_{4}\right)_{3} \cdot$ ethanol (III)}

$106 \mathrm{mg} \mathrm{Li}_{3} \mathrm{Fe}\left(\mathrm{C}_{2} \mathrm{O}_{4}\right)_{3}$ and 5 drops of 12-crown-4 crown ether were mixed in $20 \mathrm{~mL}$-carvone and $20 \mathrm{~mL}$ ethanol for three hours. A constant current of $0.1 \mu \mathrm{A}$ was passed through the solution in a $\mathrm{H}$-shaped cell and black crystals grew on the anode and were collected after 1 month.

\section{Physical measurements}

Two-probe DC transport measurements were made on several crystals of both I-III using a HUSO HECS 994C multi-channel conductometer. Gold wires (15 $\mu \mathrm{m}$ diameter) were attached to the crystal, and the attached wires were connected to a fourpin integrated circuit plug with gold conductive cement.

\section{Discussion}

Radical cation salts I-III all consist of alternating layers of tris(oxalato)metallate and BEDT-TTF. The anionic layers for I contain a novel honeycomb network of $\mathrm{Li}^{+}$and $\mathrm{M}$ (oxalate) ${ }_{3}{ }^{3-}$ with includes a water molecule which elongates the hexagon in one direction ( $\mathrm{Li} \cdots \mathrm{Fe}$ distances of 5.33(1), 5.31(1) and 8.00(1) $\AA)$. The anionic layers for II and III contain a honeycomb network of $\mathrm{Li}^{+}$and $\mathrm{M}$ (oxalate $)_{3}{ }^{3-}$ with a guest molecule situated in the hexagonal cavity. The $\mathrm{Li} \cdots \mathrm{M}$ distances are shorter than the $\mathrm{O} \cdots \mathrm{M}$ or $\mathrm{K} \cdots \mathrm{M}$ distances found in the $\beta^{\prime \prime}$ superconducting phases where $\mathrm{H}_{3} \mathrm{O}^{+}, \mathrm{NH}_{4}{ }^{+}$or $\mathrm{K}^{+}$is the counter cation. The resulting hexagonal cavities are therefore smaller in size in these lithium salts and smaller guest molecules are possible in these salts. This is similar to the sodium salts previously reported with nitromethane and dichloromethane, ${ }^{9}$ as opposed to the $\beta^{\prime \prime}$ phases where larger guests such as benzonitrile, nitrobenzene or chlorobenzene are included. ${ }^{1-5}$

$\boldsymbol{\eta}$-(BEDT-TTF $)_{4}\left(\mathrm{H}_{2} \mathrm{O}\right) \mathbf{L i F e}\left(\mathrm{C}_{2} \mathrm{O}_{4}\right)_{3}$ (I) crystallises in monoclinic space group $P 2_{1} / c$ (Fig. 1$)$. The asymmetric unit of I consists of four crystallographically independent BEDT-TTFs which adopt an $\eta$ packing motif (Fig. 2). Within each of the donor stacks there are no close S...S contacts below the van der Waals distance. There are a large number side-to-side contacts between donor stack with the shortest contact of S7 $\cdots \mathrm{S} 11$ 3.29(1) A. From the donor $\mathrm{C}=\mathrm{C}$ and $\mathrm{C}-\mathrm{S}$ bond lengths ${ }^{14}$ (Table 1) it can be approximated that the four crystallographically independent BEDT-TTF molecules have charges of $0.74^{+}$, $0.39^{+}, 0.43^{+}$and $0.39^{+}$. An overall charge on (BEDT-TTF $)_{4}$ of $1.95^{+} \pm 0.4$ is constent with the formula with $\left[\left(\mathrm{H}_{2} \mathrm{O}\right) \mathrm{LiFe}-\right.$ $\left.\left(\mathrm{C}_{2} \mathrm{O}_{4}\right)_{3}\right]^{2-}$.

Each anionic layer in I consists of alternating segregated rows of either $\Delta$ - or $\Lambda$ - $\mathrm{Fe}\left(\mathrm{C}_{2} \mathrm{O}_{4}\right)_{3}$ to give an overall racemic lattice. Unlike any salt found previously in this family the honeycomb network created by the $\mathrm{Fe}^{3+}$ and $\mathrm{Li}^{+}$is elongated along the $c$ axis by the inclusion of $\mathrm{a}_{2} \mathrm{O}$ molecule in the same cavity where $\mathrm{Li}^{+}$is located (Fig. 3). On the other hand, the large hexagonal cavity is empty as shown in Fig. 3 although the cavity is occupied by an incorporated solvent molecule in the previously obtained oxalate salts. A PLATON SQUEEZE analysis suggests that the void size is $165 \AA$ A where approximetry 60

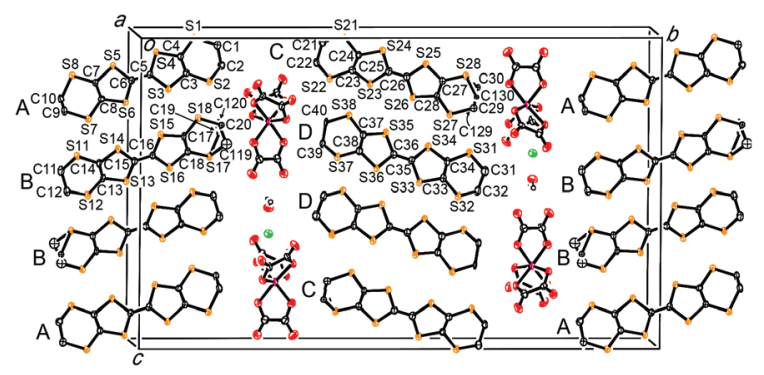

Fig. 1 Layered structure of I showing atomic labels of four crystallographically independent BEDT-TTF molecules, A, B, C and D. Hydrogens apart from those of water molecules are omitted for clarity. 


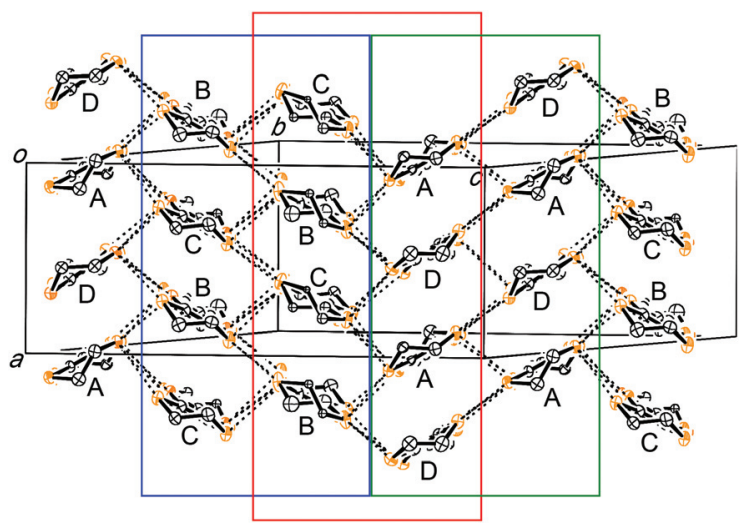

Fig. 2 BEDT-TTF layer of I viewed along the molecular long axis with S...S contacts below the sum of the van der Waals radii $(<3.7 \AA$ A). Hydrogens are omitted for clarity. The donors surrounded by blue and green squares are arranged with $\beta^{\prime \prime}$-type packing motifs. However, the blue donors and green donors are not parallel, the dihedral angles of which are approximately $120^{\circ}\left(118.4-121.7^{\circ}\right)$. Therefore, the donors surrounded by a red square have an $\alpha$-type packing motif. The donor packing arrangement has been previously observed in $\eta$-(BEDT-TTF $)_{2}\left[\mathrm{Au}(\mathrm{CN})_{2}\right]$ and $\alpha^{\prime \prime}-(\mathrm{BEDT}-\mathrm{TTF})_{2} \mathrm{KCu}(\mathrm{SCN})_{4}$. We hereafter call this packing type $\eta$-type. M. Kurmoo, P. Day, T. Mitani, H. Kitagawa, H. Shimoda, D. Yoshida, P. Guionneau, Y. Barrans, D. Chasseau, and L. Ducasse, Bull. Chem. Soc. Jpn., 1996, 69, 1233. H. Mori, T. Okano, N. Sakurai, S. Tanaka, K. Kajita, and H. Moriyama, Chem. Lett., 1998, 505.

electrons exists (see supplementary cif file). We used two solvents, $\mathrm{CH}_{3} \mathrm{CN}$ and $\mathrm{CH}_{2} \mathrm{Cl}_{2}$, the electron numbers of which are 21 and 48 , respectively. So we guess that the void is occupied by $\mathrm{CH}_{2} \mathrm{Cl}_{2}$ that is heavily disordered. It was not possible to resolve the highly disordered solvent molecules within the hexagonal cavities. This makes the $R$-value relatively high. Two-probe resistivity measurements were made on a single crystal and show that $\mathbf{I}$ is a semiconductor with an activation energy of $0.080 \mathrm{eV}$ and a room temperature resistivity of $\rho_{\mathrm{RT}}$ of $2.41 \mathrm{Ohm} \mathrm{cm}$.

$(\text { BEDT-TTF })_{3} \operatorname{LiCr}\left(\mathrm{C}_{2} \mathrm{O}_{4}\right)_{3} \cdot$ ethanol (II) and (BEDT-TTF) ${ }_{3} \mathrm{LiFe}-$ $\left(\mathrm{C}_{2} \mathrm{O}_{4}\right)_{3} \cdot$ ethanol (III) (Fig. 4-6) are isostructural and both crys-

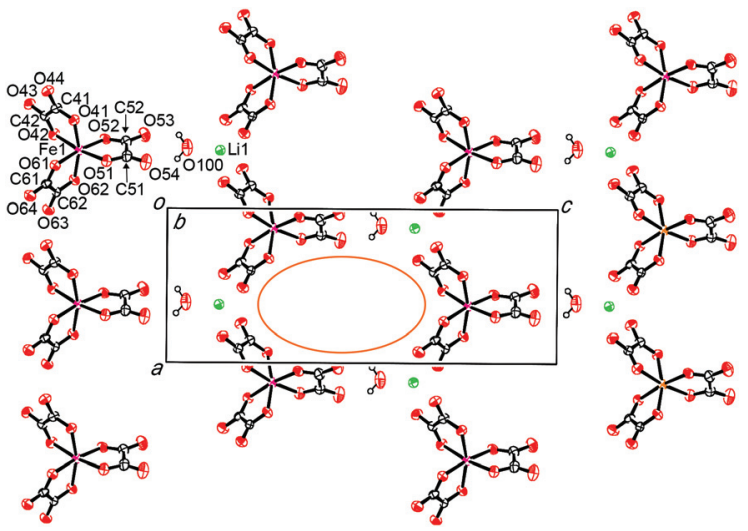

Fig. 3 Anion layer of I viewed down the $c$ axis with atomic labels. The orange ellipsoid indicates a void (see text).

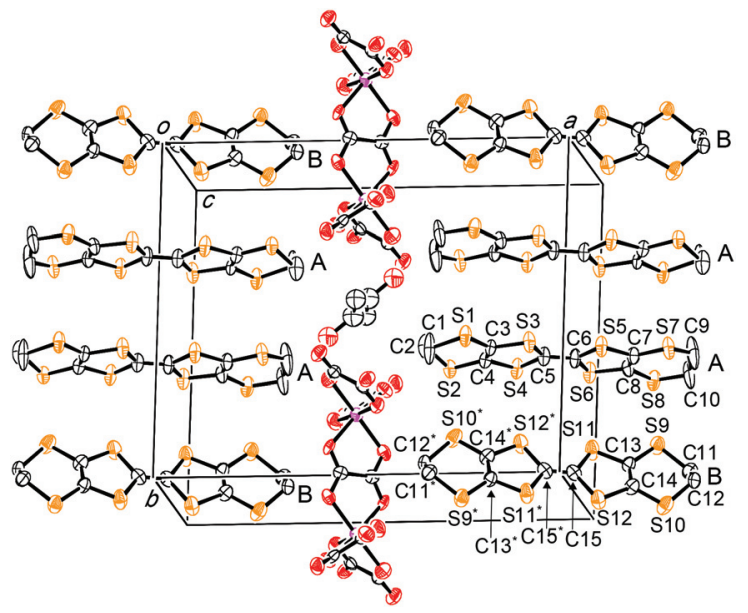

Fig. 4 Layered structure of II showing atomic labels of two crystallographically independent BEDT-TTF molecules, A and B. The structure of II is isomorphous to that of III and both numbering schemes are also the same. Hydrogens are omitted for clarity.

Table 1 Average bond lengths in BEDT-TTF molecules of I-III and approximation of charge on the molecules. $\delta=(b+c)-(a+d)$, $Q=$ $6.347-7.463 \delta^{14}$<smiles>C1CSC2=C(S1)SC(=C1SC3=C(SCCS3)S1)S2</smiles>

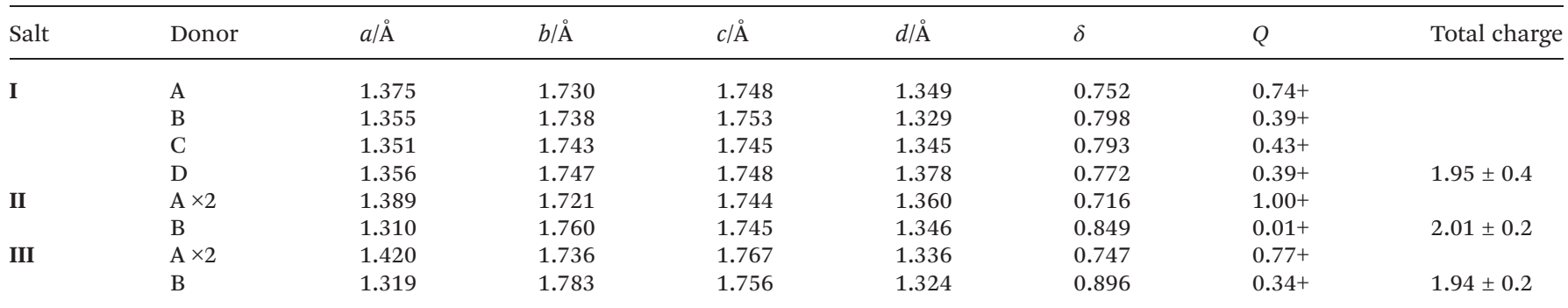




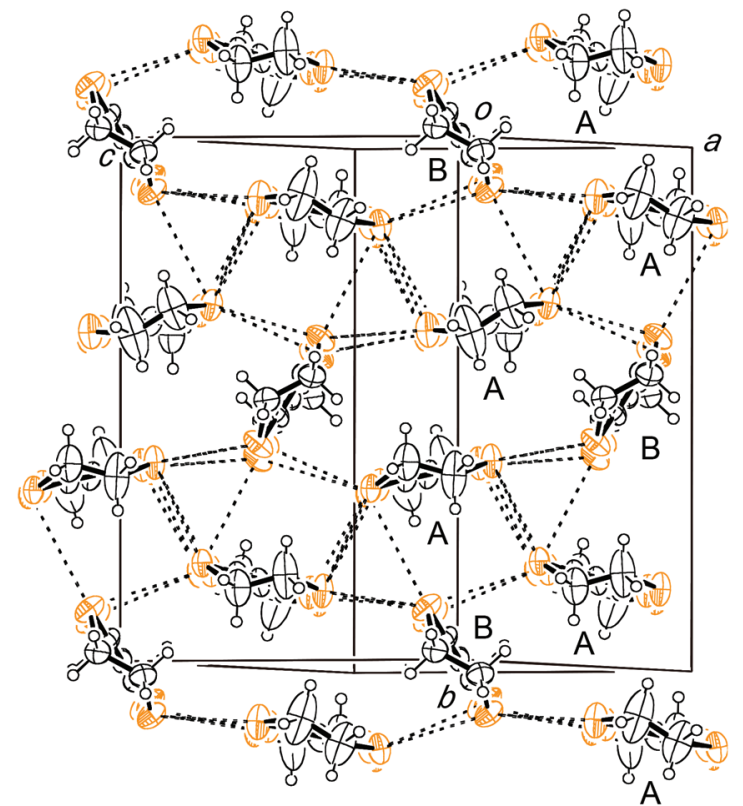

Fig. 5 BEDT-TTF layer of II viewed along the molecular long axis with S...S contacts below the sum of the van der Waals radii $(<3.7 \AA)$. The donor arrangements of II and III are both the same.

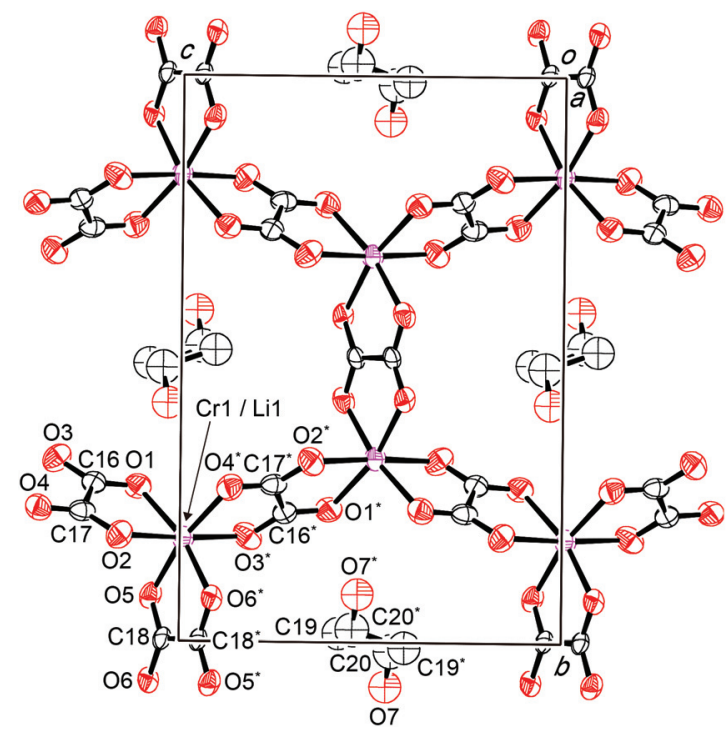

Fig. 6 Anion layer of II viewed down the $c$ axis with atomic labels. Hydrogens are omitted for clarity. The atomic coordinates and the numbering schemes of II and III are both the same.

tallise in monoclinic space group $P 2_{1} / c$. They are isostructural with (BEDT-TTF) ${ }_{3} \mathrm{NaCr}\left(\mathrm{C}_{2} \mathrm{O}_{4}\right)_{3} \cdot \mathrm{CH}_{3} \mathrm{NO}_{2}{ }^{9}$ reported previously which crystallises in the space group $P 2_{1}$. Both the sodium and lithium analogues were synthesised from carvone as the electrolyte which has been shown to produce chiral materials in this family. The sodium analog is a racemic twin containing only a single enantiomer of $\mathrm{D}-\mathrm{Cr}\left(\mathrm{C}_{2} \mathrm{O}_{4}\right)_{3}{ }^{3-}$, whilst in II and III there is $50: 50$ disorder of the $\mathrm{M}^{3+}$ : Li sites giving an overall
Table 2 S...S contacts shorter than the van der Waals distance for II and III

\begin{tabular}{|c|c|c|}
\hline & II & III \\
\hline $\mathrm{S} 1 \cdots \mathrm{S} 10$ & $3.43(1)$ & $3.49(1)$ \\
\hline $\mathrm{S} 1 \cdots \mathrm{S} 12$ & $3.47(1)$ & $3.52(1)$ \\
\hline S5 $\cdots$ S9 & $3.57(1)$ & $3.64(1)$ \\
\hline S7 $\cdots$ S9 & $3.49(1)$ & $3.57(1)$ \\
\hline
\end{tabular}

racemic lattice. The ethanol guest molecule is situated in the hexagonal cavity disordered over two sites with $\mathrm{OH}$ groups protruding out on both sides of the anion layer (Fig. 4).

The same donor packing motif is observed for both II and III, which are isostructural with (BEDT-TTF $)_{3} \mathrm{NaCr}\left(\mathrm{C}_{2} \mathrm{O}_{4}\right)_{3}$. $\mathrm{CH}_{3} \mathrm{NO}_{2}{ }^{9}$ Pairs of donor molecules (A) are parallel to one another (B) with a third molecule twisted at $45^{\circ}$ with respect to the other pair (Fig. 5). There are no face-to-face close S...S contacts between the BEDT-TTF A donors but there are four sideto-side close contacts between the two crystallographically

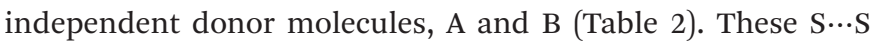
contacts are all shorter in the chromium salt II compared to the iron salt III.

Table 1 shows the $\mathrm{C}=\mathrm{C}$ and $\mathrm{C}-\mathrm{S}$ bond lengths for both $\mathbf{I I}$ and III. For each $\left[\operatorname{LiM}\left(\mathrm{C}_{2} \mathrm{O}_{4}\right)_{3}\right]^{2-}$ unit there are three BEDT-TTF molecules, two of which have a charge close to $1^{+}$with the other one having a charge close to 0 . Therefore the A donor is a cation and forms a diamagnetic spin dimer, whilst the $\mathrm{B}$ donor is neutral and surrounded by the A dimers. Such a charge disproportionation gives poor conductivity. These donor charges shows a significant difference compared to the isostructural sodium salt (BEDT-TTF $)_{3} \mathrm{NaCr}\left(\mathrm{C}_{2} \mathrm{O}_{4}\right)_{3} \cdot \mathrm{CH}_{3} \mathrm{NO}_{2}$ where charges on each of the three donor molecules are calculated as $0.77^{+}, 0.75^{+}$, and $0.55^{+}$. giving a total of $2.07^{+} \pm 0.3$.

Two-probe resistivity measurements were made on a single crystal and show that both II and III are semiconductors. Salt II has an activation energy of $0.129 \mathrm{eV}$ and a room temperature resistivity of $\rho_{\mathrm{RT}}$ of $197 \mathrm{Ohm} \mathrm{cm}$, whilst III has an activation energy of $0.126 \mathrm{eV}$ and $\rho_{\mathrm{RT}}$ of $98.1 \mathrm{Ohm} \mathrm{cm}$. By comparison the isostructural sodium salt (BEDT-TTF $)_{3} \mathrm{NaCr}\left(\mathrm{C}_{2} \mathrm{O}_{4}\right)_{3}$. $\mathrm{CH}_{3} \mathrm{NO}_{2}$ has an activation energy of $0.079 \mathrm{eV}$ and $\rho_{\mathrm{RT}}$ of $22 \mathrm{Ohm} \mathrm{cm}$.

\section{Conclusions}

We have synthesized the first examples of radical-cation salts of BEDT-TTF with tris(oxalato)metallates having lithium as the counter cation. In salt I a novel anion layer packing arrangement is observed with a hexagonal cavity which is elongated in one direction and leads to a donor packing motif not previously observed in this family of salts. Salts II and III have smaller hexagonal cavities than observed in previous salts of this family and have a preference for smaller solvents such as ethanol. Salts II and III have been synthesized using L-carvone as electrolyte which has previously led to chiral $\left[\mathrm{Cr}\left(\mathrm{C}_{2} \mathrm{O}_{4}\right)_{3}\right]^{3-}$ 
layers in the isostructural sodium salt, (BEDT-TTF) ${ }_{3} \mathrm{NaCr}-$ $\left(\mathrm{C}_{2} \mathrm{O}_{4}\right)_{3} \cdot \mathrm{CH}_{3} \mathrm{NO}_{2}$. However, the lithium salts reported here exist as a 50:50 racemic mixture owing to the disorder of the $\mathrm{Li}^{+}$ and $\mathrm{M}^{3+}$ sites within the anionic layers. Future work will investigate the inclusion of other electrolytes into salts of LiM$\left(\mathrm{C}_{2} \mathrm{O}_{4}\right)_{3}$ with BEDT-TTF to see if chirality can be observed.

Crystal data: I: $\mathrm{C}_{46} \mathrm{H}_{34} \mathrm{Fe}_{1} \mathrm{Li}_{1} \mathrm{O}_{13} \mathrm{~S}_{32}, \quad M=1883.44$, dark brown blade, $a=8.7086(5), b=37.248(2), c=22.1051(14) \AA, \alpha=$ 90, $\beta=90.193(3), \gamma=90^{\circ}, U=7170.4(8) \AA^{3}, T=120(2) \mathrm{K}$, space group $P 2_{1} / n, Z=4, \mu=1.199 \mathrm{~mm}^{-1}$, reflections collected = 64973 , independent reflections $=16261, R_{1}=0.1023, \mathrm{w} R_{2}=$ $0.1930\left[F^{2}>2 \sigma\left(F^{2}\right)\right], R_{1}=0.1341, \mathrm{w} R_{2}=0.2080$ (all data).

All hydrogen atoms were fixed using a standard riding model.

There was some highly disordered solvent within the oxalate cavities which could not be resolved and thus removed from the calculations using the SQUEEZE program.

Crystal data: II: $\mathrm{C}_{38} \mathrm{H}_{30} \mathrm{Cr}_{1} \mathrm{Li}_{1} \mathrm{O}_{13} \mathrm{~S}_{24}, M=1891.68$, black plate, $a=18.198(6), b=14.951(4), c=10.109(3) \AA, \alpha=90, \beta=$ 93.127(6), $\gamma=90^{\circ}, U=2746.2(14) \AA^{3}, T=296(2) \mathrm{K}$, space group $P 2{ }_{1} / c, Z=2, \mu=14.977 \mathrm{~cm}^{-1}$, reflections collected $=12600$, independent reflections $=4754, R_{1}=0.0975[I>2 \sigma I], R_{1}=$ $0.1512, \mathrm{w}_{2}=0.2349$ (all data).

Crystal data: III: $\mathrm{C}_{38} \mathrm{H}_{30} \mathrm{Fe}_{1} \mathrm{Li}_{1} \mathrm{O}_{12} \mathrm{~S}_{24}, M=1891.68$, black plate, $a=18.491(11), b=15.146(9), c=10.292(6) \AA, \alpha=90, \beta=$ 93.363(16), $\gamma=90^{\circ}, U=2873(3) \AA^{3}, T=302(2) \mathrm{K}$, space group $P 2_{1} / c, Z=2, \mu=11.905 \mathrm{~cm}^{-1}$, reflections collected $=21364$, independent reflections $=6489, R_{1}=0.1309[I>2 \sigma I], R_{1}=$ $0.2330, \mathrm{w}_{2}=0.3672$ (all data).

Crystals of I were run on Bruker-Nonius KappaCCD diffractometer with Mo rotating anode, using standard control and processing software. All structures were solved and refined with programs from the SHELX family.

Crystals of II and III were run using a Rigaku Mercury II CCD configured with the Rigaku MicroMax-007HF generator and VariMax confocal mirror, at room temperature. Control of the machine and the data processing were performed by the Rigaku CrystalClear ${ }^{\circledR}$ software package. The structures were solved using SIR92 for II and SIR 2008 for III and refined by SHELX2013 and the Rigaku CrystalStructure ${ }^{\circledR}$ software package.

CCDC 1042692, 1042693 and 1042696 contains supplementary X-ray crystallographic data for I, II and III.

LM thanks the Royal Society of Chemistry for a Journals Grant for International Authors. This work has been supported by the Royal Society [Research Grants (RG100853 and RG081209), International Exchange Scheme (IE130367), and International Joint Project (JP0869972)]. We thank EPSRC for funding the National Crystallography Service.

\section{Notes and references}

1 M. Kurmoo, A. W. Graham, P. Day, S. J. Coles, M. B. Hursthouse, J. L. Caulfield, J. Singleton, F. L. Pratt, W. Hayes, L. Ducasse and P. Guionneau, J. Am. Chem. Soc., 1995, 117, 12209; E. Coronado, S. Curreli, C. Giménez-Saiz and C. J. Gómez-García, J. Mater. Chem., 2005, 15, 1429.
2 L. Martin, S. S. Turner, P. Day, F. E. Mabbs and E. J. L. McInnes, Chem. Commun., 1997, 1367; S. Rashid, S. S. Turner, P. Day, J. A. K. Howard, P. Guionneau, E. J. L. McInnes, F. E. Mabbs, R. J. H. Clark, S. Firth and T. Biggs, J. Mater. Chem., 2001, 11, 2095.

3 H. Akutsu, A. Akutsu-Sato, S. S. Turner, D. Le Pevelen, P. Day, V. Laukhin, A.-K. Klehe, J. Singleton, D. A. Tocher, M. R. Probert and J. A. K. Howard, J. Am. Chem. Soc., 2002, 124(42), 12430; T. Prokhorova, L. I. Buravov, E. B. Yagubskii, L. V. Zorina, S. V. Simonov, R. P. Shibaeva and V. N. Zverev, Eur. J. Inorg. Chem., 2014, 24, 3933.

4 L. Martin, S. S. Turner, P. Day, P. Guionneau, J. K. Howard, D. E. Hibbs, M. E. Light, M. B. Hursthouse, M. Uruichi and K. Yakushi, Inorg. Chem., 2001, 40, 1363.

5 T. G. Prokhorova, L. V. Zorina, S. V. Simonov, V. N. Zverev, E. Canadell, R. P. Shibaeva and E. B. Yagubskii, CrystEngComm, 2013, 15, 7048.

6 B. Zhang, Y. Zhang and D. Zhu, Chem. Commun., 2012, 48, 197.

7 S. S. Turner, P. Day, D. E. Hibbs, K. M. A. Malik, M. B. Hursthouse, S. J. Teat, E. J. MacLean, L. Martin and S. A. French, Inorg. Chem., 1999, 38, 3543; S. Rashid, S. S. Turner, D. Le Pevelen, P. Day, M. E. Light, M. B. Hursthouse, S. Firth and R. J. H. Clark, Inorg. Chem., 2001, 40, 5304; T. G. Prokhorova, S. S. Khasanov, L. V. Zorina, L. I. Buravov, V. A. Tkacheva, A. A. Baskakov, R. B. Morgunov, M. Gener, E. Canadell, R. P. Shibaeva and E. B. Yagubskii, Adv. Funct. Mater., 2003, 13, 403; E. Coronado, S. Curreli, C. Giménez-Saiz and C. J. GómezGarcía, J. Mater. Chem., 2005, 14, 1429.

8 T. G. Prokhorova, L. I. Buravov, E. B. Yagubskii, L. V. Zorina, S. S. Khasanov, S. V. Simonov, R. P. Shibaeva, A. V. Korobenko and V. N. Zverev, CrystEngComm, 2011, 13, 537.

9 L. Martin, P. Day, P. Horton, S. Nakatsuji, J. Yamada and H. Akutsu, J. Mater. Chem., 2010, 20, 2738; L. Martin, P. Day, S. Nakatsuji, J. Yamada, H. Akutsu and P. Horton, CrystEngComm, 2010, 12, 1369; L. Martin, H. Akutsu, P. Horton and M. B. Hursthouse, CrystEngComm, 2015, DOI: 10.1039/C5CE00121H.

10 L. V. Zorina, S. S. Khasanov, S. V. Simonov, R. P. Shibaeva, V. N. Zverev, E. Canadell, T. G. Prokhorova and E. B. Yagubskii, CrystEngComm, 2011, 13, 2430.

11 H. Akutsu, A. Akutsu-Sato, S. S. Turner, P. Day, E. Canadell, S. Firth, R. J. H. Clark, J.-i. Yamada and S.-i. Nakatsuji, Chem. Commun., 2004, 18; L. Martin, P. Day, H. Akutsu, J. Yamada, S. Nakatsuji, W. Clegg, R. W. Harrington, P. N. Horton, M. B. Hursthouse, P. McMillan and S. Firth, CrystEngComm, 2007, 9, 865.

12 L. Martin, S. S. Turner, P. Day, K. M. A. Malik, S. J. Coles and M. B. Hursthouse, Chem. Commun., 1999, 513; L. Martin, S. S. Turner and P. Day, Synth. Met., 1999, 102, 1638.

13 J. C. Bailar and E. M. Jones, Inorg. Synth., 1939, 1, 1993.

14 P. Guionneau, C. J. Kepert, D. Chasseau, M. R. Truter and P. Day, Synth. Met., 1997, 86, 1973. 